\title{
A rare case of neuroleptic malignant syndrome without elevated serum creatine kinase
}

\author{
This article was published in the following Dove Press journal: \\ Neuropsychiatric Disease and Treatment \\ 24 February 2014 \\ Number of times this article has been viewed
}

\author{
Koichi Nisijima \\ Katutoshi Shioda \\ Department of Psychiatry, Jichi \\ Medical University, Tochigi, Japan
}

Correspondence: Koichi Nisijima

Department of Psychiatry, Jichi Medical University, Yakushiji Shimotuke-Shi

Tochigi-Ken, 329-0498, Japan

Tel +8I 285587364

Fax+8I 285446198

Email midorin@jichi.ac.jp

\begin{abstract}
Neuroleptic malignant syndrome (NMS) is a life-threatening adverse reaction to antipsychotic drugs. Although there is no specific examination able to diagnose NMS, serum creatine kinase (CK) elevation has been reported in over $90 \%$ of NMS patients. In this report, we describe a patient who developed NMS but had normal CK levels. The patient presented with hyperthermia of over $38^{\circ} \mathrm{C}$, severe muscle rigidity, autonomic dysfunction, and altered mental status. Although serum CK levels were measured three times during the course of NMS, the levels were within the normal range. The patient died of respiratory failure 13 days after the onset of NMS symptoms. As patients without elevated serum CK levels are rarely reported, we discuss potential reasons why the serum CK was not elevated in our patient. This case shows clinicians that although serum CK elevation is a useful indicator for the early detection of NMS, the diagnosis of NMS must be determined by clinical symptoms as otherwise, the appropriate treatment procedures for NMS may be delayed.
\end{abstract}

Keywords: malnutrition, NMS, CK, hyperthermia

\section{Introduction}

Neuroleptic malignant syndrome (NMS) is the most serious side effect of neuroleptics. Hyperthermia, severe muscle rigidity, autonomic dysfunction, and altered mental status are the four main clinical symptoms of NMS. ${ }^{1}$ Laboratory findings of patients with NMS frequently show elevated serum creatine kinase (CK) levels and leukocytosis. Specifically, elevated serum CK levels have been reported in more than $90 \%$ of cases. ${ }^{2,3}$ However, quite recently, we encountered an NMS patient without elevated serum CK.

In order to determine whether there were other NMS patients without elevated CK, we reviewed the literature surrounding NMS, utilizing the most commonly searched databases, including MEDLINE ${ }^{\circledR}$, from 1980 to October 2013, with keywords such as "neuroleptic malignant syndrome" and "creatine kinase". As a result, we identified a case report entitled "Neuroleptic Malignant Syndrome with Normal Creatine Kinase". Additionally, we read the abstracts of a case report and case series we found using the keyword "neuroleptic malignant syndrome" and checked a few hundred articles on NMS we had previously collected. Consequently, we found another NMS patient without elevated CK. ${ }^{5}$ Thus, patients without elevated serum CK levels are rarely reported. Furthermore, it is still unclear why serum CK is not elevated in some NMS patients.

When a patient taking antipsychotics presents with fever and muscle rigidity, it is important to determine whether serum CK levels are elevated as this is a useful indicator 
in the early detection of NMS. ${ }^{6}$ However, the diagnosis of NMS should mainly be determined by clinical symptoms. The case presented herein demonstrates the importance of not relying solely on increased serum CK to diagnose NMS as this may delay the diagnosis and appropriate treatment procedures. This case may be instructive to other clinicians regarding the proper diagnosis of NMS.

\section{Case report}

A 51-year-old man had experienced repetitive manic and delirious episodes since he was 17 years old and was previously diagnosed with schizoaffective disorder. He had to be psychiatrically hospitalized six times for recurrent psychotic episodes after discontinuing his medications. He did not have a history of drug allergies. In 1996, at the age of 34, he was admitted to a psychiatric hospital, where he remained until the time of the current report. At the time of admission, his height and weight was $172 \mathrm{~cm}$ and $63 \mathrm{~kg}$, respectively. His body mass index (BMI) was $21.3 \mathrm{Kg} / \mathrm{m}^{2}$. Throughout the first year of admission, he suffered repeated manic episodes with excitement and delusion. During these episodes, he often had to be taken into a private room because of his violent behavior towards other patients. Since he often refused to take medications, he was given fluphenazine decanoate ( $25 \mathrm{mg}$ ), injected intramuscularly, every month. Additionally, he was given lithium carbonate (600 mg), zotepine (150 mg), haloperidol (9 mg), and biperiden ( $6 \mathrm{mg}$ ) daily. While being treated with lithium carbonate, the serum lithium levels were within the therapeutic range. Furthermore, during periods when he became manic and excited, his dietary intake decreased, leading to large decreases in body weight. As a result, his body weight ranged from 63 to $53 \mathrm{~kg}$.

His body weight was about $55 \mathrm{~kg}$ in the first half of 2011 but was $63 \mathrm{~kg}$ in January of 2012. After this, his body weight decreased gradually along with the deterioration of his mental state, and by December of 2012, he weighed $49 \mathrm{~kg}$. His changes in BMI are shown in Figure 1. There were no complaints from the patient, but he was suspected of having malignant disease. However, blood tests showed no abnormalities: white blood cell (WBC) count 7,900/ $\mathrm{mm}^{3}$, red blood cell $(\mathrm{RBC})$ count $344 \times 10^{4} / \mathrm{mm}^{3}$, total protein $7.6 \mathrm{~g} / \mathrm{dL}$, total cholesterol $169 \mathrm{mg} / \mathrm{dL}$, aspartate aminotransferase (AST) $12 \mathrm{mU} / \mathrm{mL}$, alanine aminotransferase (ALT) $9 \mathrm{mU} / \mathrm{mL}$, and CK $51 \mathrm{mU} / \mathrm{mL}$ (normal range 48-248).

On January 31, 2013, the patient weighed $48 \mathrm{~kg}$. Upon evaluation, his blood pressure was $96 / 60 \mathrm{mmHg}$, his pulse rate was $58 \mathrm{bpm}$, and his body temperature was $35.5^{\circ} \mathrm{C}$. At that time, valproic acid (600 mg), lithium carbonate

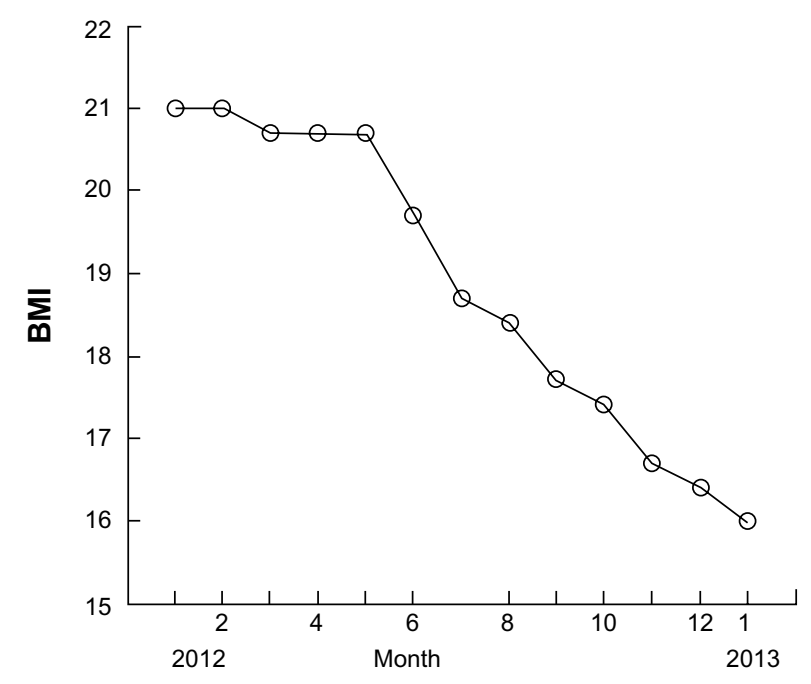

Figure I The changes in the patient's BMI throughout the previous year. Abbreviation: BMI, body mass index $\left(\mathrm{kg} / \mathrm{m}^{2}\right)$.

(800 $\mathrm{mg})$, zotepine $(150 \mathrm{mg})$, and risperidone $(6 \mathrm{mg})$ were administered. On February 11, he became excited and was physically violent towards other patients and was transferred to a private ward. On February 12, the patient received fluphenazine decanoate $(25 \mathrm{mg}$ ) by intramuscular injection. On February 13, he was physically able to have a meal by himself. On February 14, when a nurse went for her rounds in the morning, she noticed that he could not raise himself up. He did not show headaches, meningeal signs, or focal neurological signs. Upon evaluation, his blood pressure was $106 / 72 \mathrm{mmHg}$, his pulse rate was 102 bpm, and his body temperature was $36.0^{\circ} \mathrm{C}$ but rose to $38.5^{\circ} \mathrm{C}$ in the afternoon (day 1 of NMS). Since he had difficulty swallowing, all medications were discontinued, and he received intravenous fluid replacement. At that time, an antibiotic was administered intravenously upon suspicion of an infection. On February 17, it was noted that he was unable to speak due to marked muscle rigidity, but he did not show diaphoresis. His chest X-rays were normal. On February 18, blood tests showed the following: WBC

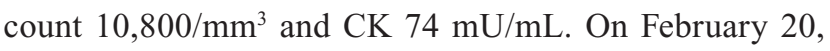
diaphoresis was observed. Since fever, generalized "lead pipe rigidity", and dysphagia were also found, NMS was suspected. Only supportive therapy, including intravenous fluid replacement and cooling, was sustained. Because his serum CK was within the normal range, we were hesitant to administer dantrolene; thus, dantrolene was not given. In addition, since the patient had been mute during the disease, the administration of benzodiazepines or electroconvulsive therapy (ECT) was not planned. Although the patient's serum $\mathrm{CK}$ was measured two more times, the levels were 
within normal range. On February 24, the patient's body temperature was $38.4^{\circ} \mathrm{C}$, and hypersalivation and tachypnea (respiratory rate 34/min) became prominent. On February 25 , his oxygen saturation was noted to be $89 \%$ with room air, and $100 \% \mathrm{O}_{2}$ was immediately given via face mask. However, he suddenly died of respiratory failure on February 26 (day 13). An autopsy was not performed.

The profile of the clinical course, including body temperature, the degree of muscle rigidity, and laboratory findings consisting of the levels of serum $\mathrm{CK}$ and WBC, is shown in Figure 2. Muscle rigidity was rated using the NMS evaluation scale proposed by Sachdev. ${ }^{7}$

\section{Discussion}

The cardinal feature of the present case was the lack of elevated serum CK, found in over $90 \%$ of NMS patients.

To date, several diagnostic criteria have been proposed for NMS, including those by Levenson, ${ }^{8}$ Pope et al, ${ }^{9}$ Caroff and Mann, ${ }^{1}$ and the DSM-IV-TR. ${ }^{10}$ Since serum CK elevation is not a main symptom in the diagnostic criteria proposed by Pope et al, ${ }^{9}$ Caroff and Mann, ${ }^{1}$ or the DSMIV-TR, ${ }^{10}$ our patient can be diagnosed with NMS, using these criteria. Using the diagnostic criteria suggested by Levenson, ${ }^{8}$ our patient showed two of the main criteria, hyperthermia and muscle rigidity. The third main criterion, serum CK elevation, was not observed in our patient; however, he did demonstrate tachycardia, tachypnea, an altered mental state, diaphoresis, and leukocytosis, which are the minor symptoms. ${ }^{8}$ Since the presence of all three major or the combination of two major and four minor manifestations indicates a high probability of NMS in Levenson's diagnostic criteria, our patient can be diagnosed with NMS, using these criteria.

However, many medical conditions can mimic the presentation of NMS. One of these is central nervous system (CNS) infection. Since the patient did not show headaches, meningeal signs, or focal neurological signs, he is unlikely to have had a CNS infection. It has been reported that patients with hyperthyroidism can, albeit rarely, show NMS symptoms. ${ }^{11}$ Additionally, serum CK is often reduced in hyperthyroidism (thyrotoxicosis), ${ }^{12}$ therefore, hyperthyroidism is one potential differential diagnosis. Hyperthyroidism was ruled out because tachycardia was not found before the onset of muscle rigidity and serum cholesterol levels were within the normal range, although thyroid hormone levels were not measured. In addition, some other disease ${ }^{13}$ should have been ruled out before diagnosing our patient as a case of NMS without elevated serum CK. As discussed in more detail below, no specific blood tests were performed to rule out Cushing's syndrome, or systemic lupus erythematosus (SLE) in our patient. However, there were no physical indications of these disorders or complaints from the patient; thus, we believe the diagnosis of NMS was appropriate.

It has been established that elevated $\mathrm{CK}$ levels are found in over $90 \%$ of patients with NMS. ${ }^{1,2}$ In other words, cases of NMS without significant serum CK elevation are rarely reported. As described earlier, there have been only two reports of serum $\mathrm{CK}$ that was not elevated in patients with NMS. Singh and Hassanally ${ }^{4}$ released a case report whose title included the description, "normal CK". Additionally, Nielsen and Bruhn ${ }^{5}$ reported a case of NMS without CK elevation.

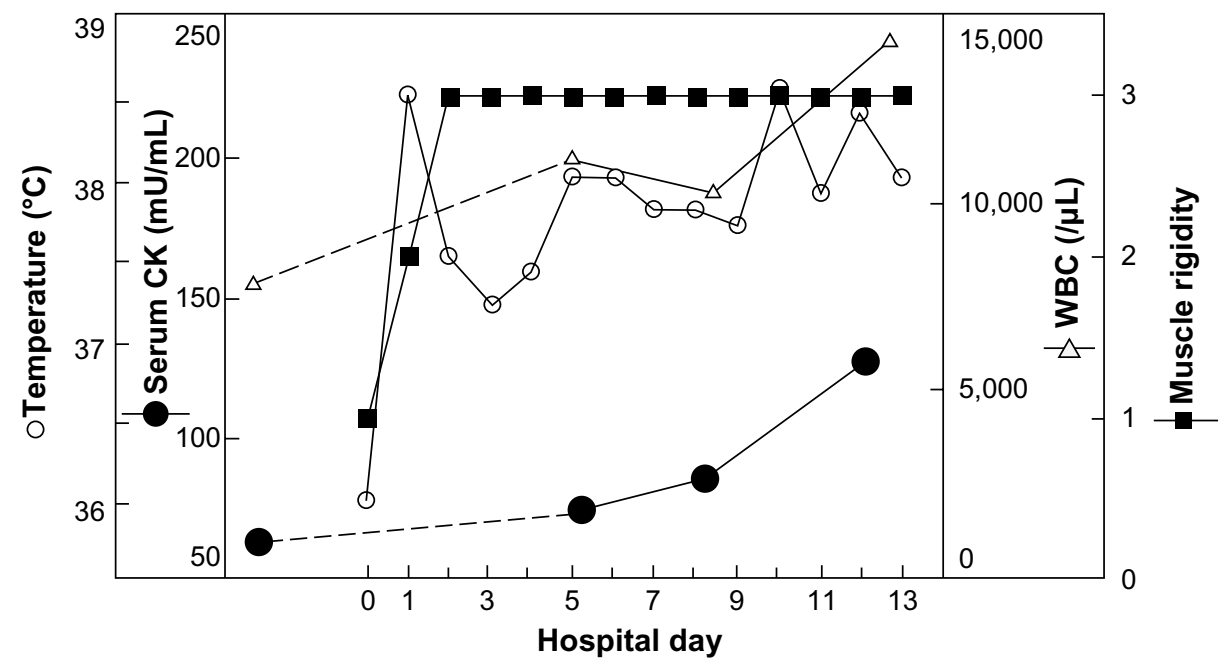

Figure 2 The clinical course of the patient's body temperature $(O)$, degree of muscle rigidity $(\square)$, and laboratory findings, including the levels of serum $C K(\mathbf{)})$ and WBC $(\triangle)$. Note: Muscle rigidity was rated using the NMS evaluation scale proposed by Sachdev. ${ }^{7}$

Abbreviations: CK, creatine kinase; NMS, neuroleptic malignant syndrome; WBC, white blood cells. 
We recently published a paper showing how serum CK levels changed during the course of NMS in 24 patients. ${ }^{6}$ Out of 24 patients, none of the patients showed normal CK levels. The patient described herein is the first patient with NMS that we have identified as having a normal CK level. Therefore, NMS patients without elevated serum CK levels are rare, emphasizing the importance of discussing why our NMS patient did not show elevated serum CK levels. Singh and Hassanally, ${ }^{4}$ who reported one NMS patient with normal CK levels, were unable to establish why serum CK was not elevated in their patient. In the case report presented by Nielsen and Bruhn, ${ }^{5}$ the authors postulated that serum CK was not elevated because the muscle rigidity in their patient was not severe. In the case of our patient, muscle rigidity was reasonably severe, and thus, the speculation by Nielsen and $\mathrm{Bruhn}^{5}$ does not apply. It is known that there are some clinical conditions associated with normal or low values of CK..$^{12,13}$ For example, in physical illnesses, such as Cushing's disease, SLE, and liver diseases, or in patients receiving certain drugs, such as corticosteroids, estrogen, and cancer chemotherapy. Although the specific blood tests for the above diseases were not performed, there is a low possibility that our patient had these illnesses because he did not have physical complaints and his clinical evaluations were normal. In addition, it was reasonably certain that he did not take specific drugs such as corticosteroids.

As shown in Figure 2, the levels of serum CK in the patient were measured three times, and the level gradually increased. It is possible that if serum CK had been measured a fourth time, the level would have exceeded the normal range. However, he died of respiratory failure 13 days after the development of NMS.

On the other hand, low serum CK levels have been reported in patients with muscle wasting and low body muscular mass. ${ }^{12,13}$ When the patient developed NMS, his weight had decreased to $48 \mathrm{~kg}$ (BMI $=16.2)$, as shown in Figure 1, and was accompanied by a deterioration in his psychiatric status. Therefore, it is possible that his extreme decreased body mass may be related to the observed normal CK levels. Additionally, it has been reported that several clinical factors, including physical exhaustion and dehydration, are correlated with the development of NMS. ${ }^{14}$ Although antipsychotic drugs had been administered and fluphenazine decanoate had been given to the patient once a month from the age of 34, the patient did not have a past history of NMS. Because his extreme decreased body mass may be related to the clinical factors for developing NMS, it is possible that he developed NMS under the above physical condition, while serum CK levels remained within the normal range. At this time, we cannot concretely conclude why serum $\mathrm{CK}$ was not elevated. More cases with normal CK levels are needed in order to discuss which factors may be associated with normal CK in NMS.

As serum CK is generally elevated in the early stage of NMS, ${ }^{6}$ it can be an indicator in early detection of NMS. However, the case described here shows that a definitive diagnosis of NMS has to be determined from clinical symptoms; otherwise, the appropriate procedures for treating NMS might be delayed.

\section{Disclosure}

The authors report no conflicts of interest in this work.

\section{References}

1. Caroff SN, Mann SC. Neuroleptic malignant syndrome. Med Clin North Am. 1993;77(1):185-202.

2. Addonizio G, Susman VL, Roth SD. Neuroleptic malignant syndrome: review and analysis of 115 cases. Biol Psychiatry. 1987;22(8): 1004-1020.

3. Caroff SN, Mann SC. Neuroleptic malignant syndrome. Psychopharmacol Bull. 1988;24(1):25-29.

4. Singh R, Hassanally D. Neuroleptic malignant syndrome with normal creatine kinase. Postgrad Med J. 1996;72(845):187.

5. Nielsen J, Bruhn AM. Atypical neuroleptic malignant syndrome caused by olanzapine. Acta Psychiatr Scand. 2005;112(3):238-240; discussion 240 .

6. Nisijima K, Shioda K. Temporal changes in serum creatine kinase concentration and degree of muscle rigidity in 24 patients with neuroleptic malignant syndrome. Neuropsychiatr Dis Treat. 2013;9:853-859.

7. Sachdev PS. A rating scale for neuroleptic malignant syndrome. Psychiatry Res. 2005;135(3):249-256.

8. Levenson JL. Neuroleptic malignant syndrome. Am J Psychiatry. 1985;142(10):1137-1145.

9. Pope HG, Keck PE, McElroy SL. Frequency and presentation of neuroleptic malignant syndrome in a large psychiatric hospital. Am J Psychiatry. 1986;143(10):1227-1233.

10. American Psychiatric Association. Diagnostic and Statistical Manual of Mental Disorders: DSM-IV-TR. Washington, DC: American Psychiatric Association; 2000.

11. Rudolf J, Grond M, Neveling M, Heiss WD. Catatony in Graves' disease. Eur Psychiatry. 1998;13(8):419-420.

12. Rosalki SB. Low serum creatine kinase activity. Clin Chem. 1998; 44(5):905

13. Gran JT, Gunnarsson R, Mørk NJ. [A man with erythrodermia, muscle weakness and weight loss]. Tidsskr Nor Laegeforen. 2009;129(21): 2240-2241. Norwegian.

14. Strawn JR, Keck PE Jr, Caroff SN. Neuroleptic malignant syndrome. Am J Psychiatry. 2007;164(6):870-876. 
Neuropsychiatric Disease and Treatment

Dovepress

\section{Publish your work in this journal}

Neuropsychiatric Disease and Treatment is an international, peerreviewed journal of clinical therapeutics and pharmacology focusing on concise rapid reporting of clinical or pre-clinical studies on a range of neuropsychiatric and neurological disorders. This journa is indexed on PubMed Central, the 'PsycINFO' database and CAS

The manuscript management system is completely online and includes a very quick and fair peer-review system, which is all easy to use. Visit http://www.dovepress.com/testimonials.php to read real quotes from published authors.

Submit your manuscript here: http://www.dovepress.com/neuropsychiatric-disease-and-treatment-journal 